\title{
RESEARCH
}

Open Access

\section{Synergistic interaction between APOE and family history of Alzheimer's disease on cerebral amyloid deposition and glucose metabolism}

Dahyun $\mathrm{Yi}^{1}$, Younghwa Lee ${ }^{2}$, Min Soo Byun ${ }^{1}$, Jun Ho Lee ${ }^{2}$, Kang Ko ${ }^{2}$, Bo Kyung Sohn ${ }^{3}$, Young Min Choe ${ }^{4}$, Hyo Jung Choi ${ }^{5}$, Hyewon Baek ${ }^{6}$, Chul-Ho Sohn ${ }^{7}$ Yu Kyeong Kim ${ }^{8}$, Dong Young Lee ${ }^{1,2,9^{*}}$ and for the KBASE research group

\begin{abstract}
Background: Recently, the field of gene-gene or gene-environment interaction research appears to have gained growing interest, although it is seldom investigated in Alzheimer's disease (AD). Hence, the current study aims to investigate interaction effects of the key genetic and environmental risks - the apolipoprotein $\varepsilon 4$ allele (APOE4) and family history of late-onset $A D(F H)$ - on AD-related brain changes in cognitively normal (CN) middle-aged and older adults.

Methods: $\left[{ }^{11} \mathrm{C}\right]$ Pittsburg compound-B (PiB) positron emission tomography (PET) imaging as well as $\left[{ }^{18} \mathrm{~F}\right]$ fluoro-2deoxyglucose (FDG) PET that were simultaneously taken with T1-weighted magnetic resonance imaging (MRI) were obtained from 268 CNs from the Korean Brain Aging Study for Early Diagnosis and Prediction of AD (KBASE). Composite standardized uptake value ratios were obtained from PiB-PET and FDG-PET images in the AD signature regions of interests (ROIs) and analyzed. Voxel-wise analyses were also performed to examine detailed regional changes not captured by the ROI analyses.

Results: A significant synergistic interaction effect was found between the APOE4 and FH on amyloid-beta (Aß) deposition in the AD signature ROls as well as other regions. Synergistic interaction effects on cerebral glucose metabolism were observed in the regions not captured by the AD signature ROls, particularly in the medial temporal regions.
\end{abstract}

Conclusions: Strong synergistic effects of APOE4 and FH on A $\beta$ deposition and cerebral glucose metabolism in CN adults indicate possible gene-to-gene or gene-to-environment interactions that are crucial for pathogenesis of $A D$ involving A $\mathrm{A}$. Other unspecified risk factors - genes and/or environmental - that are captured by the positive FH status might either coexpress or interact with APOE4 to alter AD-related brain changes in CN. Healthy people with both FH and APOE4 need more attention for AD prevention.

Keywords: APOE, Family history of Alzheimer's disease, Cognitively normal adults, Amyloid beta deposition, Cerebral glucose metabolism

\footnotetext{
* Correspondence: selfpsy@snu.ac.kr

The coinvestigators of the KBASE Research Group are listed in Additional file 1 (Coinvestigators).

'Institute of Human Behavioral Medicine, Medical Research Center Seoul

National University, Seoul, Republic of Korea

2Department of Neuropsychiatry, Seoul National University Hospital, Seoul,

Republic of Korea

Full list of author information is available at the end of the article
}

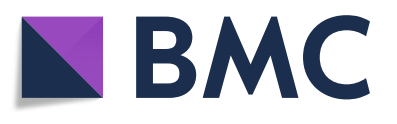

(c) The Author(s). 2018 Open Access This article is distributed under the terms of the Creative Commons Attribution 4.0 International License (http://creativecommons.org/licenses/by/4.0/), which permits unrestricted use, distribution, and reproduction in any medium, provided you give appropriate credit to the original author(s) and the source, provide a link to the Creative Commons license, and indicate if changes were made. The Creative Commons Public Domain Dedication waiver (http://creativecommons.org/publicdomain/zero/1.0/) applies to the data made available in this article, unless otherwise stated. 


\section{Background}

Decades of research on sporadic late-onset Alzheimer's disease (AD) dementia, the most common form of dementia, have shown that AD dementia is a multifactorial disease with a wide variety of genetic and environmental factors playing a role in the age of onset, risk, and etiology [1]. Numerous heritable and inheritable risk factors have been linked with AD pathogenesis. Nevertheless, to date, only a limited number of studies have investigated the interaction effect between the major risks on in-vivo AD-related brain changes which can reflect the pathogenesis of AD. Information about whether the major risks of AD dementia can synergistically increase $\mathrm{AD}$-specific brain changes before the onset of dementia symptoms will likely help identification of a more urgent target population for the preventive efforts against AD dementia.

The apolipoprotein $\varepsilon 4$ allele (APOE4) is a major risk factor for $\mathrm{AD}$ dementia and is associated with a decade or more mean age at onset decrease in $\mathrm{AD}$ symptoms [2]. Numerous studies have reported a relationship between APOE4 and AD-related brain changes such as increased amyloid-beta $(\mathrm{A} \beta)$ deposition and decreased glucose metabolism even in cognitively normal $(\mathrm{CN})$ elderly individuals, although with some inconsistencies in the degree of effects [3-9]. Notably, functional brain abnormalities associated with APOE4 as identified by decreased cerebral glucose metabolism in the AD-related brain regions were found in healthy volunteers even as young as 20-39 years old [10]. Furthermore, a recent meta-analysis has shown strong effects of APOE4 on not only the prevalence of amyloid pathology but also the age of onset of AD dementia [11]. Despite some inconsistencies, the presence of strong effects of APOE4 on $\mathrm{A} \beta$ deposition and cerebral glucose metabolism has been repeatedly and undeniably shown.

In recent years, evidence has accumulated for other genetic and environmental factors that influence AD-related brain changes [1]. Having a first-degree family history of $\mathrm{AD}$ dementia $(\mathrm{FH})$ is another well-known risk factor for developing AD dementia and is considered to encapsulate both genetic and environmental risk loads [12] as it not only captures heritable genetic susceptibility but also other shared dietary, psychosocial, and somatic factors that are shown to be associated with an individual's risk for developing AD dementia [13-15]. Similar to APOE4, the effects of FH on AD-related brain changes including $A \beta$ deposition and glucose metabolism are present even in $\mathrm{CN}$ individuals, although less consistently [16-18].

Previous research shows that FH and APOE4 highly co-occur $[19,20]$ and, conceivably, their effects on developing $\mathrm{AD}$ dementia may overlap. However, given that they reflect different hereditary factors (i.e., genetic only or both genetic and environmental), it is likely that an interaction of the effects of $\mathrm{FH}$ and APOE4 exists for AD-related brain changes such that having both $\mathrm{FH}$ and APOE4 will lead to synergistic influences on AD-related brain changes compared to when an individual has only one of the two risk factors. Nonetheless, to the best of our knowledge, no study has examined the synergistic interaction effects of $\mathrm{FH}$ and APOE4 on AD-related brain changes, specifically $\mathrm{A} \beta$ deposition and glucose metabolism, in cognitively intact adults. In this context, the purpose of the current study was to test the hypothesis that APOE4 and FH have synergistic interaction effects on cerebral $A \beta$ deposition and glucose metabolism in healthy middle-aged and older adults.

\section{Methods \\ Subjects}

This study is a part of the Korean Brain Aging Study for the Early Diagnosis and Prediction of AD (KBASE), an ongoing prospective cohort study that began in 2014 designed to identify novel biomarkers for AD and to explore various lifetime experiences contributing to AD-related brain changes. The current study included 268 community-dwelling $\mathrm{CN}$ individuals, between 50 years and 87 years of age, who were recruited as of March 2016. Details on the KBASE study characteristics including recruitment have been described previously [21]. Individuals with medical, psychiatric, and/or neurological conditions or history of conditions that may affect brain structures or functions, such as stroke, head trauma, depression, hydrocephalus, or focal brain lesions on magnetic resonance imaging (MRI) were excluded. All subjects had reliable informants available who provided corroborative information on the family history of medical conditions, including the presence of $\mathrm{AD}$ dementia. Subjects had a Clinical Dementia Rating of 0 and performed within the normal range relative to age-, gender-, and education-adjusted normative means on comprehensive neuropsychological assessments [22, 23]. The study was ethically reviewed and all participants provided written informed consent to participate in this study after receiving a complete description of the study, which is approved by Seoul National University Hospital Institutional Review Board.

\section{Assessments}

Comprehensive clinical and neuropsychological assessment data were obtained from all participants based on the KBASE assessment protocol that incorporated and expanded upon the Korean version of the Consortium to Establish a Registry for Alzheimer's Disease assessment packet (CERAD-K) [22, 24]. A detailed description of the cognitive assessments has been previously reported [21]. Briefly, the assessments included the Mini-Mental State 
Examination in the Korean version of the CERAD assessment packet (MMSE-KC), the CERAD-K verbal memory tests, including Word List Memory, Word List Delayed Recall, Word List Recognition, CERAD-K Constructional Praxis, and CERAD-K nonverbal memory delayed recall, the Trail Making Test A and B, and the Stroop Test (Korean Golden version), Verbal Fluency Tasks (both semantic and phonemic), the CERAD-K confrontational naming test (Modified Korean version of the Boston Naming Test), and the Wechsler Adult Intelligence Scale-revised edition Korean version (WAIS-R-K) Digit Span (forward and backward). Neuropsychological test performances are presented as $z$ scores based on age-, gender-, and education-adjusted normative data [24].

Genomic DNA was extracted from whole blood and APOE genotyping was performed [25]; subjects with at least one $\varepsilon 4$ allele were identified as APOE4 carriers. For the majority of participants, cognitive assessments were administered on the same day that the neuroimaging scans were conducted; four individuals underwent cognitive assessment and neuroimaging scans on different dates where the interval was less than 1 month.

\section{Family history of AD}

Subjects and reliable informants were administered a semistructured interview by trained psychiatrists or a registered nurse to gather detailed information of any family history of dementia. Participants were asked: 1) if any of their birth parents, natural grandparents, siblings sharing parents, or other relatives had dementia and/or other type of neurological diseases; 2) if so, what was the diagnosis of the affected relative and the age of onset; 3 ) whether or not the affected family member is deceased; and 4), if deceased, what was the age at death.

Positivity of $\mathrm{FH}$ was determined if at least one first-degree relative (parent or sibling) had $\mathrm{AD}$ onset at 65 years of age or older and whose diagnosis had been made by a certified clinician. If formal diagnosis for a parent was unavailable due to their old age or age at death that preceded implementation of the established criteria in hospital, participants were asked additional questions to determine if their parent exhibited the symptoms of AD dementia such as cognitive and functional decline consistent with the criteria in the absence of other known causes that could preclude an AD diagnosis; if sufficient information was gathered and findings were deemed consistent with a diagnosis of $\mathrm{AD}$, these subjects were also identified as $\mathrm{FH}$-positive $\left(\mathrm{FH}^{+}\right)$. If none of the first-degree relatives was identified as having $\mathrm{AD}$ dementia, subjects were classified as $\mathrm{FH}$-negative $\left(\mathrm{FH}^{-}\right)$.

\section{Amyloid-beta imaging}

All subjects underwent three-dimensional $\left[{ }^{11} \mathrm{C}\right]$ Pittsburg compound $\mathrm{B}(\mathrm{PiB})$ positron emission tomography (PET) imaging simultaneously taken with T1-weighted MRI at 3.0 $\mathrm{T}$ using a Biograph mMR (PET-MR) scanner (Siemens, Washington DC, USA). Preprocessing steps were performed using Statistical Parametric Mapping 12 (SPM12) (see Additional file 1: Methods for more detail).

Spatial normalization processes were performed on PiB-PET data using Statistical Parametric Mapping 12 (http://www.fil.ion.ucl.ac.uk/spm/software/spm12/) (SPM12) implemented in Matlab 2014a (Mathworks, MA). Static PiB-PET images were coregistered to individual T1 structural images, and transformation parameters for spatial normalization of individual T1 images to a standard MNI (Montreal Neurological Institute) template were calculated, which were then used to spatially normalize the PET images to the MNI template. The spatially normalized PiB-PET images were smoothed with an 8-mm Gaussian filter.

Additional processes were run for PiB-PET data to obtain improved spatial normalization of cerebellar gray matter, which is used as the reference region for intensity normalization (see Additional file 1: Methods section of the online data supplement for more detail).

The $\mathrm{PiB}$ retention index as the standardized uptake value ratio (SUVR) for each region of interest (ROI) was calculated by dividing the regional mean value by the individual mean cerebellar uptake values. The automatic anatomic labeling algorithm [26] and a region combining method [27] were applied to set the ROIs to characterize $\mathrm{PiB}$ retention level in frontal, lateral parietal, posterior cingulate-precuneus (PC-PRC), and lateral temporal regions. Each participant was classified as $\mathrm{A} \beta$-positive if the SUVR value was $>1.4$ in at least one of the four ROIs or as $A \beta$-negative if the SUVR values of all four ROIs was $\leq 1.4$ [27, 28]. For the ROI analyses, a voxel-number weighted average SUVR of a composite global ROI was calculated using the four ROIs $\left(\mathrm{AD}_{\mathrm{PiB}}-\mathrm{ROI}\right)$.

\section{Cerebral glucose imaging}

All subjects also underwent three-dimensional $\left[{ }^{18} \mathrm{~F}\right]$ fluoro-2-deoxyglucose (FDG) PET taken using the same PET-MR scanner as the PiB-PET. The acquisition parameters were similar to the PiB-PET procedures (described in more detail in Additional file 1: Methods).

In terms of spatial normalization processes performed on FDG-PET data, basic preprocessing was the same as for PiB-PET described above. The spatially normalized FDG-PET images were smoothed with a 12-mm Gaussian filter. For FDG-PET images, intensity normalization was performed on spatially normalized images using pons as the reference region, and SUVRs were extracted for ROIs using the standard AAL 116 atlas. For the ROI analyses, a voxel-number weighted average SUVR of a composite ROI ( $\mathrm{AD}_{\mathrm{FDG}}-\mathrm{ROI}$ ) including middle temporal gyrus, posterior cingulate cortex (PCC), and fusiform gyrus was 
calculated, which are the regions known to be sensitive to metabolic changes associated with AD [17].

\section{Statistical analysis}

Analyses were performed with SPSS 23.0 and SPM12. The APOE genotypes were coded as APOE4 carrier $\left(\mathrm{APOE}^{+}\right)$or noncarrier $\left(\mathrm{APOE} 4^{-}\right)$. Differences in clinical and ROI measures between the $\mathrm{FH}$ groups as well as the APOE4 groups were examined with independent sample $t$ tests, a general linear model (GLM), and $\chi^{2}$ tests. Main effects and interaction were examined in the model, adjusting for age and gender effects. Post-hoc tests for an interaction effect were performed using Dunn-Sidak correction for multiple comparisons. In addition, the APOE4 carrier status was added as a covariate for main effects model of FH; likewise, the FH status was added to covariates for the main effects model of APOE4. Results were examined at $p<0.05$.

To explore the interaction effects with more detailed regional information, the GLM was used to test for regional differences in parametric PiB and FDG SUVR images using SPM12. Results were initially examined at $p<0.005$, uncorrected for multiple comparisons. A significant cluster was identified based on a cluster correction procedure available in the Analysis of Functional NeuroImage (3dClustSim, version built 4 November 2016), which performed 10,000 iterations of Monte Carlo simulations on anatomical mask datasets with $1,801,748$ voxels. This method, derived from Gaussian Random Field Theory, protects against multiple comparisons [29]. The cluster size threshold to achieve correction for multiple comparisons at $p<0.05$ was calculated to be $k>1062$ voxels.

\section{Results}

\section{Participant characteristics}

Demographic characteristics are shown in Table 1. Of the 268 study participants, 51 (19\%) had at least one first-degree family member with a history of late-onset AD. Each participant was identified into one of the four groups: $\mathrm{FH}^{-} \mathrm{APOE} 4^{-}, \quad \mathrm{FH}^{+} \mathrm{APOE} 4^{-}, \quad \mathrm{FH}^{-} \mathrm{POE} 4^{+}$, or $\mathrm{FH}^{+} \mathrm{APOE} 4^{+}$. There were no differences between the groups regarding age, gender distribution, education, or cognitive functioning. The total allele frequency of APOE4 in this cohort was $9 \%$, which is consistent with a

Table 1 Subject characteristics by family history and APOE4 groups

\begin{tabular}{|c|c|c|c|c|c|}
\hline & $\mathrm{FH}^{-} \mathrm{APOE} 4^{-}$ & $\mathrm{FH}^{+} \mathrm{APOE} 4^{-}$ & $\mathrm{FH}^{-} \mathrm{APOE} 4^{+}$ & $\mathrm{FH}^{+} \mathrm{APOE} 4^{+}$ & $P$ \\
\hline$n$ & 180 & 38 & 37 & 13 & \\
\hline Age (years), mean (SD) & $68.2(8.2)$ & $65.2(9.5)$ & $69.6(9.4)$ & $68.2(9.5)$ & 0.41 \\
\hline Gender, female/male (\% female) & $97 / 83(53.9)$ & $15 / 23(39.5)$ & 20/17 (54.1) & $6 / 7(46.2)$ & 0.12 \\
\hline Education (years), mean (SD) & $11.9(4.9)$ & $13.4(4.1)$ & $11.0(4.1)$ & $12.2(4.4)$ & 0.15 \\
\hline APOE4 dosage, $n$ of $\varepsilon 4 / \varepsilon 4$ (\%) & $0(0)$ & $0(0)$ & $0(0)$ & $2(15)$ & \\
\hline MMSE (raw score), mean (SD) & $27.0(2.4)$ & $27.5(2.4)$ & $26.2(2.9)$ & $27.3(2.5)$ & 0.11 \\
\hline \multicolumn{6}{|c|}{ Neuropsychological test performance (z score, mean (SD)) } \\
\hline Immediate Verbal Memory Free Recall & $0.88(0.96)$ & $0.86(0.98)$ & $0.60(1.02)$ & $0.81(0.73)$ & 0.46 \\
\hline Delayed Verbal Memory Free Recall & $0.41(0.87)$ & $0.54(0.89)$ & $0.29(0.90)$ & $0.53(0.62)$ & 0.60 \\
\hline Delayed Verbal Memory Recognition & $0.19(0.78)$ & $0.28(0.65)$ & $-0.003(0.84)$ & $0.27(0.69)$ & 0.40 \\
\hline Delayed Nonverbal Memory & $0.33(0.92)$ & $0.49(0.74)$ & $0.05(0.82)$ & $0.45(0.58)$ & 0.14 \\
\hline Semantic Fluency & $0.30(1.12)$ & $0.51(1.18)$ & $-0.09(0.80)$ & $0.75(1.58)$ & 0.05 \\
\hline Confrontational Naming & $0.52(0.89)$ & $0.65(0.63)$ & $0.35(0.87)$ & $0.87(0.58)$ & 0.22 \\
\hline Constructional Praxis & $-0.04(0.93)$ & $0.21(0.66)$ & $-0.08(1.13)$ & $-0.10(1.04)$ & 0.46 \\
\hline Stroop Color-Word & $0.23(1.04)$ & $0.45(0.91)$ & $-0.001(0.76)$ & $0.27(0.91)$ & 0.27 \\
\hline Trail Making Test A & $0.65(1.93)$ & $1.03(0.46)$ & $0.48(1.91)$ & $0.85(0.50)$ & 0.54 \\
\hline Trail Making Test $\mathrm{B}^{\mathrm{a}}$ & $0.89(1.04)$ & $1.40(0.85)$ & $0.94(1.14)$ & $0.96(0.73)$ & 0.11 \\
\hline Digit Span Forward & $0.36(1.07)$ & $0.52(0.90)$ & $-0.04(0.98)$ & $0.58(0.92)$ & 0.08 \\
\hline Digit Span Backward & $0.12(1.23)$ & $0.52(1.34)$ & $-0.24(0.86)$ & $0.38(1.81)$ & 0.06 \\
\hline Amyloid-beta positive, $n$ (\%) & $19(11)$ & $5(13)$ & $7(19)$ & $5(38)^{*}$ & 0.03 \\
\hline
\end{tabular}

APOE4 apolipoprotein $\varepsilon 4$ allele, $A P O E 4^{+}$APOE4 carrier, $A P O E 4^{-}$APOE4 noncarrier, $F H$ parental or sibling (first-degree relative) family history of late-onset AD (age of onset $\geq 65$ years), $\mathrm{FH}^{+}$positive $\mathrm{FH}, \mathrm{FH}^{-}$negative $\mathrm{FH}, \mathrm{MMSE}$ Mini-Mental State Examination, $\mathrm{SD}$ standard deviation

${ }^{a} 35 \%$ of $\mathrm{FH}^{-} \mathrm{APOE}^{-}, 24 \%$ of $\mathrm{FH}^{+} \mathrm{APOE} 4^{-}, 59 \%$ of $\mathrm{FH}^{-} \mathrm{APOE} 4^{+}$, and $38 \%$ of $\mathrm{FH}^{+} \mathrm{APOE} 4^{+}$did not complete the Trail Making Test $\mathrm{B}$ due to cognitive reasons, participation refusal, or illiteracy

*Significantly different from the other groups based on post-hoc analyses, multiple comparisons corrected $(P=0.0067)$. Homozygote APOE4 carriers were not among the five amyloid-beta-positive individuals 

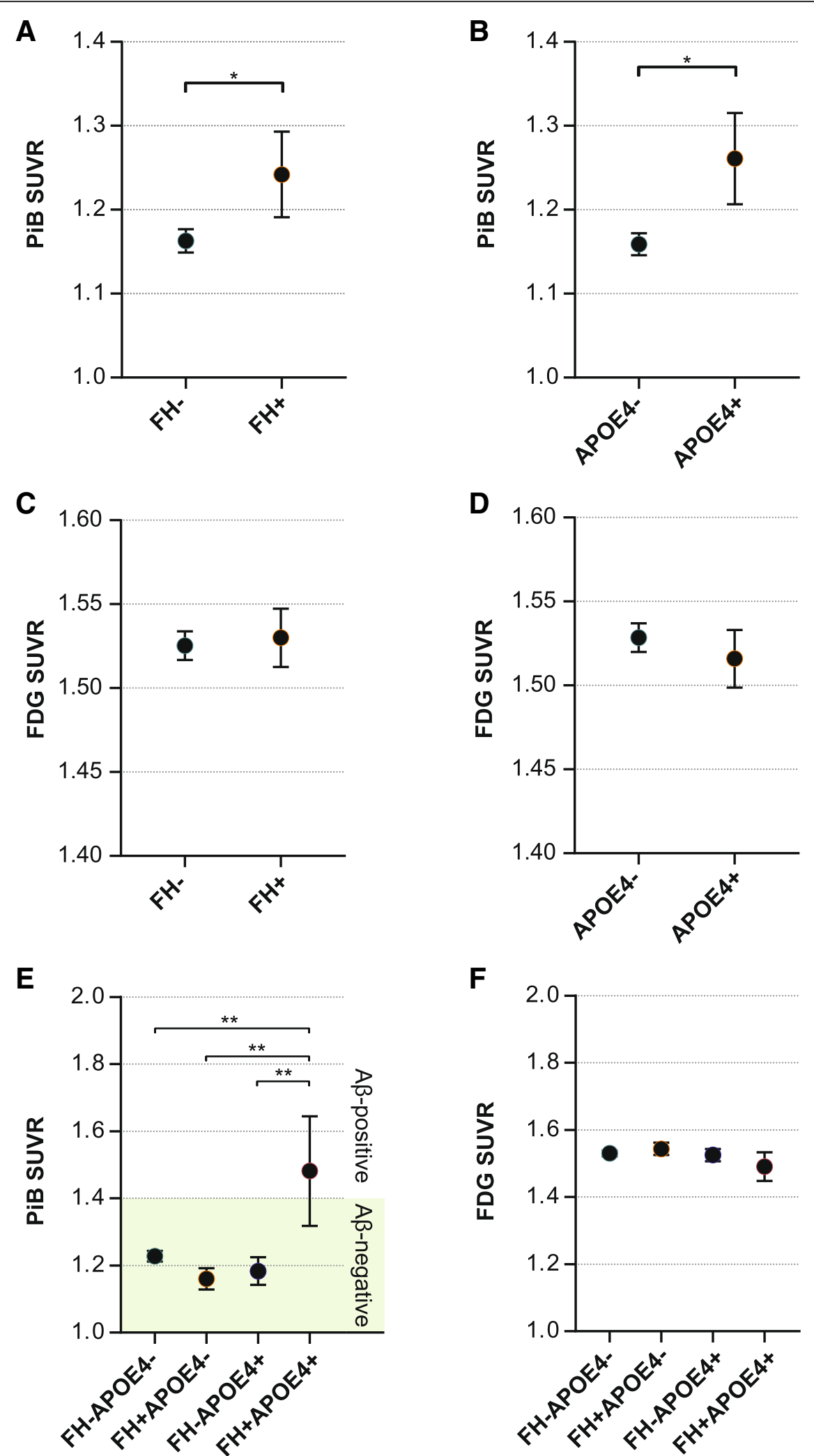

Fig. 1 (See legend on next page.) 
(See figure on previous page.)

Fig. 1 Mean PiB retention and FDG uptake SUVRs. a ADP PiB-ROI between $\mathrm{FH}^{-}$and $\mathrm{FH}^{+}$. b ADPiB $-\mathrm{ROI}$ between $A P O E 4^{-}$and $A P O E 4^{+}$. c ADFDG-ROI between $\mathrm{FH}^{-}$and $\mathrm{FH}^{+}$. $\mathbf{d} \mathrm{AD}_{\mathrm{FDG}}-\mathrm{ROI}$ between $\mathrm{APOE}^{-}$and $\mathrm{APOE}^{+}$. e Interaction effect of $\mathrm{FH}$ and $\mathrm{APOE}$ on PiB retention. $\mathbf{f}$ Interaction effect of FH and $\mathrm{APOE}$ on FDG uptake. The green shaded area in e denotes below the PiB SUVR threshold of 1.4. Error bars indicate standard error. ${ }^{*} P<0.05$; ${ }^{*}$ significant difference in the post-hoc analyses adjusted for multiple comparisons using Dunn-Sidak correction $\left(P_{B}<0.0085\right)$. A 3 amyloid beta, APOE4 apolipoprotein $\varepsilon 4$ allele, APOE4 ${ }^{+}$ APOE4 carriers, APOE4- APOE4 noncarriers, FDG $\left[{ }^{18} \mathrm{~F}\right]$ fluoro-2-deoxyglucose, $\mathrm{FH}$ family history of Alzheimer's disease, $\mathrm{FH}^{+}$individuals with $\mathrm{FH}^{-} \mathrm{FH}^{-}$ individuals without $\mathrm{FH}$, L left hemisphere, $\mathrm{PiB}\left[{ }^{11} \mathrm{C}\right]$ Pittsburg compound B, R right hemisphere, SUVR standardized uptake value ratio

previous report on APOE polymorphism among Koreans [30]. There were two APOE4 homozygote carriers in the entire sample, both of whom were $\mathrm{FH}^{+}$. The proportion of $A \beta$-positive subjects was significantly higher in the $\mathrm{FH}^{+} \mathrm{APOE} 4^{+}$group than the other groups.

\section{Independent association of FH and APOE4 on cerebral amyloid deposition}

Significant differences between $\mathrm{FH}^{-}$and $\mathrm{FH}^{+}$were found for the $A D_{\mathrm{PiB}}-\mathrm{ROI}$ (Additional file 1: Table S3 (Model-A)) and remained the same when the effect was additionally adjusted for APOE4 status (Fig. 1a; Additional file 1: Table S3 (Model-B)).

Significant differences in $A \beta$ deposition levels were found in the $\mathrm{AD}_{\mathrm{PiB}}-\mathrm{ROI}$ between the $\mathrm{APOE}^{+}$and APOE4 $4^{-}$groups (Additional file 1: Table S3 (Model-C)). Significant differences remained the same when FH status was added as a covariate (Fig. 1b; Additional file 1: Table S3 (Model-D)). Overall, PiB retention was higher in $\mathrm{FH}^{+}$compared with $\mathrm{FH}^{-}$and in $\mathrm{APOE} 4^{+}$compared with APOE4-.

\section{Independent association of FH and APOE4 on cerebral glucose metabolism}

There were no significant differences found in the $\mathrm{AD}_{\mathrm{FDG}}-\mathrm{ROI}$ between the $\mathrm{FH}$ groups (Additional file 1: Table S3 (Model-A)) or the APOE4 groups (Additional file 1: Table S3 (Model-C)). Results remained the same when APOE4 status was added as a covariate (Fig. 1c; Additional file 1: Table S3 (Model-B)) or when FH status was added as a covariate (Fig. 1d; Additional file 1: Table S3 (Model-D)).

\section{FH-APOE4 interaction effects: ROI analyses}

A significant $\mathrm{FH}-\mathrm{APOE} 4$ interaction effect was found for the $\mathrm{AD}_{\mathrm{PiB}}$-ROI $\left(F=11.51, \quad p<0.001, R^{2}=0.112\right)$ in addition to significant main effects of $\mathrm{FH}$ and APOE4 (Additional file 1: Table S1); the $\mathrm{FH}^{+} \mathrm{APOE} 4^{+}$group showed significantly higher $\mathrm{A} \beta$ deposition compared with the other groups (Fig. 1e). However, there were no main or interaction effects on regional cerebral glucose metabolism (rCMglc) between FH and APOE4 (Fig. 1f; Additional file 1: Table S1). The interaction effects remained significant when two APOE4 homozygote individuals were excluded (Additional file 1: Table S6).

\section{FH-APOE4 interaction effects: voxel-wise analyses}

Voxel-wise analyses were conducted between the $\mathrm{FH}^{+} \mathrm{A}$ $\mathrm{POE}_{4}^{+}$group and the other groups to further explore detailed brain regions showing the interaction effects on $\mathrm{A} \beta$ deposition and rCMglc. Compared with $\mathrm{FH}^{+} \mathrm{A}$ $\mathrm{POE}_{4}^{-}, \mathrm{FH}^{+} \mathrm{APOE} 4^{+}$showed increased $\mathrm{A} \beta$ deposition in the left postcentral gyrus, left superior frontal gyrus, and left precuneus (Fig. 2a); compared with $\mathrm{FH}^{-} \mathrm{APOE} 4^{+}$, $\mathrm{FH}^{+} \mathrm{APOE}^{+}$showed increased $\mathrm{A} \beta$ deposition in the left postcentral and supramarginal gyri and left superior frontal gyrus (Fig. 2b); and compared with $\mathrm{FH}^{-} \mathrm{APOE} 4^{-}$, $\mathrm{FH}^{+} \mathrm{APOE} 4^{+}$showed increased $\mathrm{A} \beta$ deposition in the left middle frontal and temporal gyri, right inferior parietal lobule, left postcentral gyrus, and left posterior cingulate gyrus (Fig. 2c). There were no regions in any of the comparisons where $\mathrm{FH}^{+} \mathrm{APOE} 4^{+}$showed lower $\mathrm{A} \beta$ deposition levels (Additional file 1: Table S4).

Although there were no significant interaction effects of FH and APOE4 on rCMglc found from the ROI analyses, voxel-wise analyses were conducted for explorative purposes since subtle changes in $\mathrm{CN}$ adults may not have been captured by the $\mathrm{AD}_{\mathrm{FDG}}$-ROI. Compared with $\mathrm{FH}^{+} \mathrm{APOE}_{4}^{-}, \mathrm{FH}^{+} \mathrm{APOE} 4^{+}$showed decreased rCMglc in the right entorhinal area and left hippocampus (Fig. 3a); compared with $\mathrm{FH}^{-} \mathrm{APOE} 4^{+}, \mathrm{FH}^{+} \mathrm{APOE} 4^{+}$showed decreased rCMglc in the right entorhinal area and inferior temporal gyrus (Fig. 3b); and compared with $\mathrm{FH}^{-} \mathrm{A}-$ $\mathrm{POE}^{-}, \mathrm{FH}^{+} \mathrm{APOE} 4^{+}$showed decreased rCMglc in the right entorhinal area (Fig. 3c). There were no regions with significant differences in any of the comparisons where $\mathrm{FH}^{+} \mathrm{APOE} 4^{+}$showed hypermetabolism compared with the other groups (Additional file 1: Table S4).

\section{Discussion}

The present study examined whether APOE4 and $\mathrm{FH}$ have synergistic interaction effects on cerebral $A \beta$ deposition and glucose metabolism in healthy middle-aged and older adults. The most notable finding was a significant increase in $\mathrm{A} \beta$ deposition if an individual was an APOE4 carrier with a positive family history for AD. While the synergistic interaction effect of $\mathrm{FH}$ and APOE4 on cerebral glucose metabolism was not found in the ROI analyses, voxel-wise analyses revealed that the synergistic interaction effect on glucose metabolism was in fact present in the temporal regions, including 


\section{A $\mathrm{FH}+\mathrm{APOE} 4+>$ FH+APOE4-}

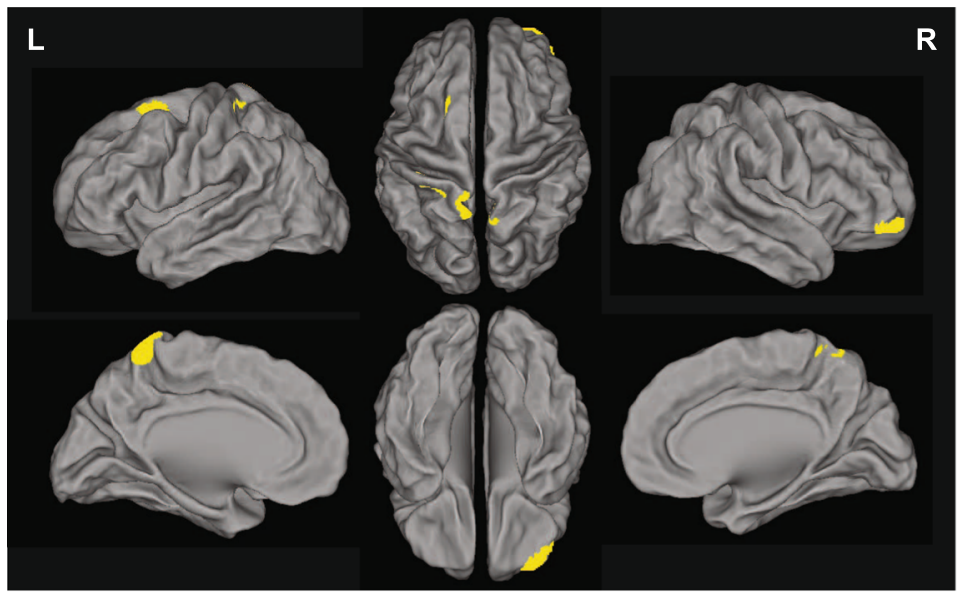

B FH+APOE4+ > FH-APOE4+

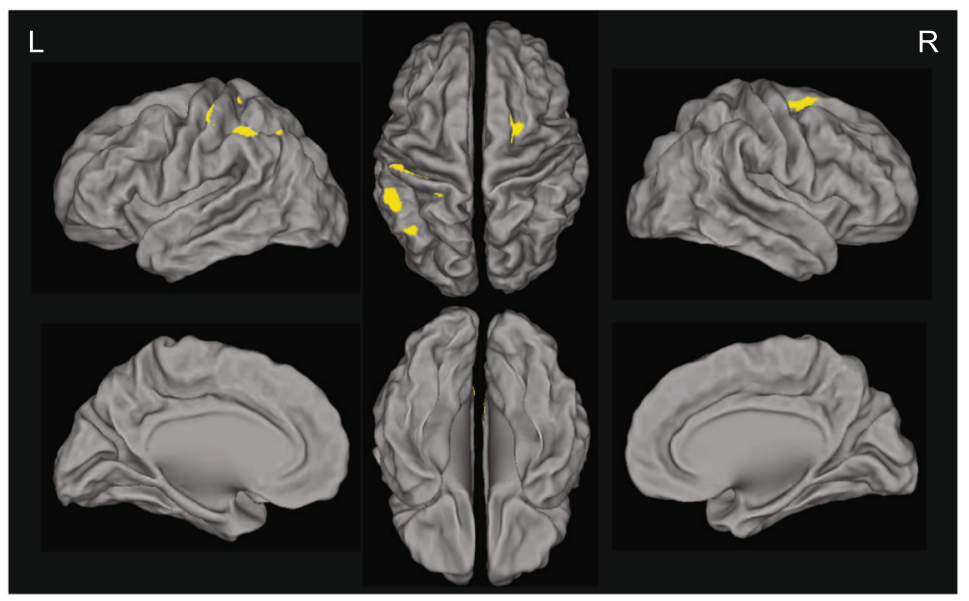

C FH+APOE4+ > FH-APOE4-

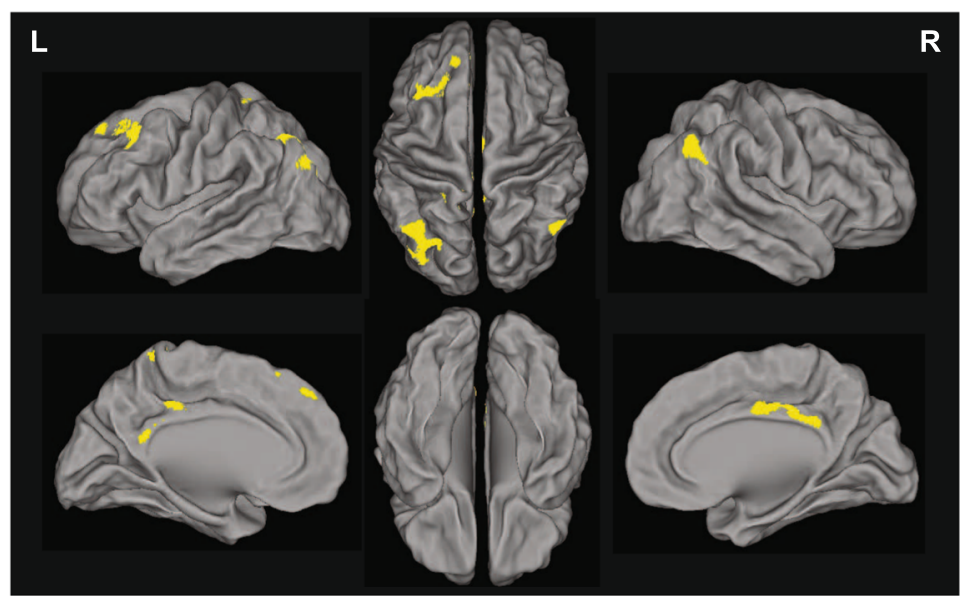

Fig. 2 (See legend on next page.) 
(See figure on previous page.)

Fig. 2 Regions showing significant differences in $A \beta$ deposition from voxel-wise analyses. a FH $H^{+} A P O E 4^{+}$compared with $F H^{+} A P O E 4^{-}$. b $\mathrm{FH}^{+} \mathrm{APOE} 4^{+}$compared with $\mathrm{FH}^{-} \mathrm{APOE} 4^{+}$. c $\mathrm{FH}^{+} \mathrm{APOE} 4^{+}$compared with $\mathrm{FH}^{-} \mathrm{APOE} 4^{-}$. A anterior, APOE4 apolipoprotein $\varepsilon 4$ allele, APOE4 ${ }^{+}$APOE4 carriers, APOE4- APOE4 noncarriers, $\mathrm{FH}$ family history of Alzheimer's disease, $\mathrm{FH}^{+}$individuals with $\mathrm{FH}, \mathrm{FH}^{-}$individuals without $\mathrm{FH}, \mathrm{L}$ left hemisphere, $\mathrm{P}$ posterior, $\mathrm{R}$ right hemisphere

the hippocampi. To the best of our knowledge, there is no previous study examining the interaction effects of APOE4 and $\mathrm{FH}$ on both $\mathrm{A} \beta$ deposition and rCMglc.

A body of literature devoted to investigating the genetic risks of AD has largely focused on either APOE4 or $\mathrm{FH}$. The current findings on the interaction effects of $\mathrm{FH}$ and APOE4 on $\mathrm{A} \beta$ deposition and rCMglc further delineate the nature of the relationship between the two risk factors on signature AD brain changes. As can be inferred from the interaction effects, differences in the proportions of $\mathrm{FH}^{+}$individuals included in the study samples may account, at least in part, for varied magnitudes of the effects of APOE4 reported in the literature. Conceivably, the commonly reported effects of APOE4 on $\mathrm{AD}$ brain biomarkers in the literature may actually be the effects seen in $\mathrm{FH}^{+} \mathrm{APOE} 4^{+}$compared with other groups. A similar argument can be made regarding the investigations of the effects of $\mathrm{FH}$ on $\mathrm{AD}$ brain biomarkers since the effects of $\mathrm{FH}$ were only seen in APOE4 carriers. Given the significant synergistic interaction effect, a simple application of statistical adjustment to achieve independency of the effects of either one of the risk factors may be misrepresenting.

A question arises as to the role played by a family history of $\mathrm{AD}$ in APOE4 carriers. The results from the current study strongly suggest that the APOE4 carriers with a family history of $\mathrm{AD}$ are more susceptible to alterations of the signature $\mathrm{AD}$ brain biomarkers before the onset of any cognitive symptoms. A positive family history status may represent other susceptibility genes that are either coexpressed or interacting with APOE4. It has been posited that gene-gene interactions account for much of the unexplained variances in $\mathrm{AD}$ status [31] and that these interactions are widespread and common [32]. For example, clusterin (CLU; involved in AD pathogenesis directly by influencing $A \beta$ aggregation and clearance [33, $34])$ is found to interact with APOE4 [35, 36]. Bridging integrator 1, whose role is implicated in tauopathy [37], is thought to interact with the CLU [38]. In addition to the known genetic risks for $\mathrm{AD}$ possibly interacting with each other, there is a possibility that $\mathrm{FH}^{+}$is capturing additional genetics that are considered unrelated to $\mathrm{AD}$ but interact with the AD genetic risks. Delineation of the role of genetics in the diagnosis and risk prediction in late-onset $\mathrm{AD}$ is complicated since up to $75 \%$ of APOE4 carriers do not develop $\mathrm{AD}$ and up to $50 \%$ of individuals with $\mathrm{AD}$ are APOE4 noncarriers $[39,40]$. A twin study that examined genetic and environmental influences on $\mathrm{AD}$ reported that additive genetic influences explain $79 \%$ of the variance in the $\mathrm{AD}$ phenotype as opposed to $21 \%$ explained by nonshared environmental influences; when shared environmental influences were added to the analysis model, however, the variance in the $\mathrm{AD}$ phenotype explained by additive genetic influences changed to $58 \%$, and $42 \%$ of the variance was explained by environmental influences (both shared (19\%) and nonshared (23\%)) [12]. Furthermore, a more recent study using the Alzheimer's Disease Genetics Consortium data and Genome-wide Complex Trait Analysis method reported that $53.24 \%$ of phenotypic variance was explained by genetics [41]. Given that

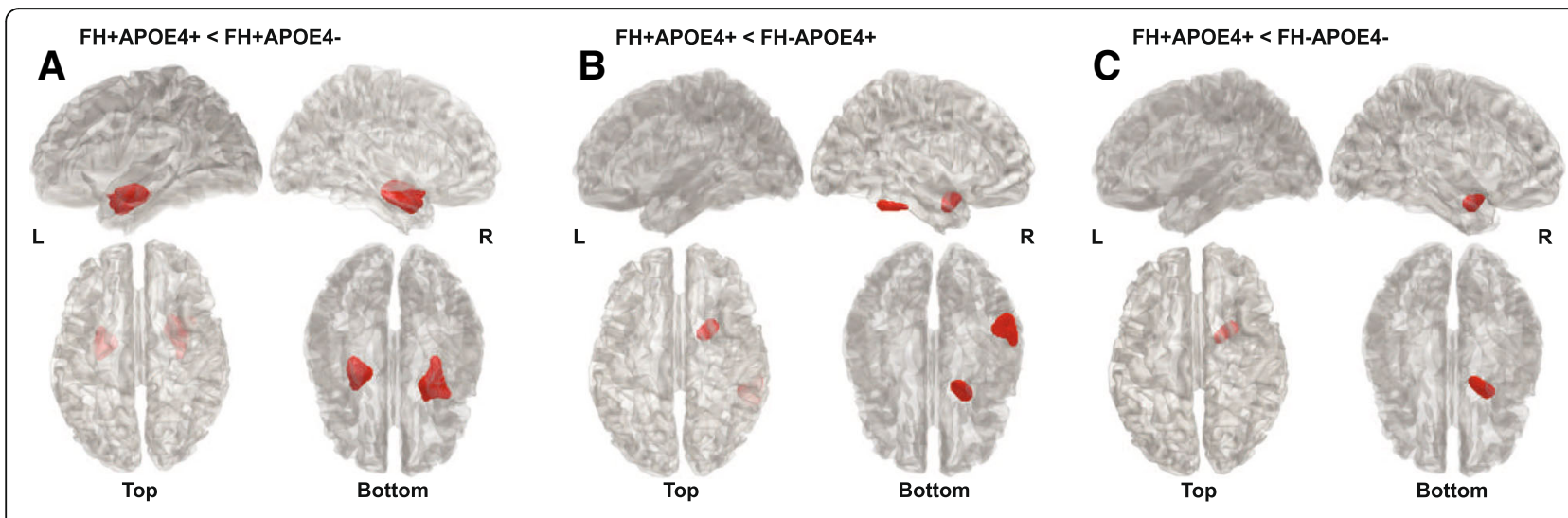

Fig. 3 Regions showing significant difference in cerebral glucose metabolism from voxel-wise analyses. a FH $\mathrm{FPOE}^{+}$compared with $\mathrm{FH}{ }^{+} \mathrm{APOE} 4^{-}$. $\mathbf{b}$ $\mathrm{FH}^{+} \mathrm{APOE} 4^{+}$compared with $\mathrm{FH}^{-} \mathrm{APOE} 4^{+}$. c $\mathrm{FH}^{+} \mathrm{APOE} 4^{+}$compared with $\mathrm{FH}^{-} \mathrm{APOE} 4^{-}$. APOE4 apolipoprotein $\varepsilon 4$ allele, APOE4 ${ }^{+}$APOE4 carriers, APOE4 ${ }^{-}$ APOE4 noncarriers, $\mathrm{FH}$ family history of Alzheimer's disease, $\mathrm{FH}^{+}$individuals with $\mathrm{FH}, \mathrm{FH}^{-}$individuals without $\mathrm{FH}, \mathrm{L}$ left hemisphere, $\mathrm{R}$ right hemisphere 
environmental factors likely can explain the variance unaccounted for by genetic risks, involvement of a family's shared environments (captured by $\mathrm{FH}^{+}$) needs to be considered carefully as they may interact with APOE4 and other genetic risks. Shared environmental factors, which are seldom reported in association with $A \beta$, include a family's socioeconomic status, place of living (e.g., urban versus rural), lifestyle or dietary habits, parents' educational attainment and intellectual environment, and exposure to pollution [42-46]. Cognitive activity during the early life stage, for example, has been found to be associated with reduced neurodegeneration in $\mathrm{AD}$ signature regions in later life [47]. Although the abovementioned environmental factors may not individually show strong effects on $\mathrm{AD}$, a combination of the environmental factors with APOE4 or other genetic risks may exhibit meaningful influences on AD neuropathology.

While independent main effects of APOE4 and FH were observed on $A \beta$ deposition, there were no differences in cerebral glucose metabolism between the $\mathrm{FH}$ groups or the APOE4 groups in the brain regions typically affected in clinical AD patients in the current sample of cognitively normal elderly whose degree of degeneration is not yet progressed enough to be detected. In line with the findings by Lowe et al. [5] who showed that most of the APOE4-related differences in hypometabolism are mediated by amyloid accumulation, hypometabolism associated with APOE4 or $\mathrm{FH}$ in the AD signature regions in the current sample was only observed in individuals with high $\mathrm{A} \beta$ deposition (Additional file 1: Figure S1, Table S5), suggesting that the effects of APOE4 or FH on cerebral glucose metabolism only begin to show when the disease is progressed. Moreover, the hypometabolic pattern observed, particularly in the medial temporal regions, in association with $\mathrm{FH}^{+}$and APOE4 $4^{+}$status (Fig. 3) is noteworthy given that these regions are where phosphorylated tau (p-tau) pathology is first to develop prior to accumulation of neurofibrillary tangles [8]. Taken together, the current cross-sectional observation in the $\mathrm{CN}$ likely reflects early observation of abnormal $A \beta$ biomarkers prior to the onset of changes in glucose metabolism in the $\mathrm{AD}$ signature regions, which supports the amyloid pathological cascade model [48].

A strength of the current study is that the study participants were recruited from the community and that the sample includes a large number of $\mathrm{APOE}_{4}^{+}$and $\mathrm{FH}^{+}$individuals despite relatively lower proportions (18\% and $19 \%$, respectively) compared with previous studies (24-43\% and up to $66 \%$, respectively) $[5,6,8,9,16,18]$. The studies based on the Alzheimer's Disease Neuroimaging Initiative (ADNI) data, for instance, frequently recruited from family members of $\mathrm{AD}$ patients such that the samples included a large proportion of $\mathrm{FH}^{+}$individuals, and these samples included a large proportion of $\mathrm{A} \beta$-positive $\mathrm{CN}$ individuals (e.g., 47\%) $[1,5,49]$, which is considerably higher than the current sample (13\%). The current findings on the independent effects of APOE4 and $\mathrm{FH}$ on $\mathrm{A} \beta$ deposition and glucose metabolism are therefore relatively robust from differences in the proportions of $\mathrm{APOE} 4^{+}$or the number of $\mathrm{FH}^{+}$individuals included in the total sample.

Similar to previous studies on $\mathrm{FH}$, steps were taken to ensure that $\mathrm{AD}$ diagnosis in the subjects' parents was accurate, such as including only the subjects whose parent's $\mathrm{AD}$ diagnosis was made by a clinician according to the established criteria. Also, in a few cases where parents were deceased before formal diagnosis was available in clinics (i.e., parents of our old-old participants), a thorough interview was conducted with family members by a psychiatrist with expertise in dementia research to sufficiently address the inclusion/exclusion criteria of the AD diagnosis. Nonetheless, our cohort may have included a few participants whose parents did not have $\mathrm{AD}$ but instead had other types of dementia since the information obtained regarding those parents without a formal diagnosis is subject to recall bias. In the future, an investigation into possible protective effects of the APOE $\varepsilon 2$ allele will allow further understanding of its role in the interaction effect of APOE and FH.

\section{Conclusions}

The current study was the first attempt to elucidate the interaction effects between $\mathrm{FH}$ and APOE4 on cerebral $\mathrm{A} \beta$ deposition and glucose metabolism in cognitively healthy adults. The strong synergistic effects of APOE4 and $\mathrm{FH}$ on brain $\mathrm{A} \beta$ deposition and hypometabolism that were found indicate possible gene-to-gene or gene-to-environment interactions that are important for the pathogenesis of AD. Such a synergistic effect also indicates that individuals with both FH and APOE4 are the population that needs more attention with regard to preventive interventions.

\section{Additional file}

Additional file 1: Supplementary material including additional methods, results, and author list for the KBASE group. (DOCX 1677 kb)

\footnotetext{
Abbreviations

$A \beta$ : Amyloid-beta; AD: Alzheimer's disease; $A D_{\text {FDG }}-R O I$ : Composite global region of interest of FDG uptake; $A D_{\mathrm{PiB}}-\mathrm{ROI}$ : Composite global region of interest of PiB retention; APOE4: Apolipoprotein $\varepsilon 4$ allele; CERADK: Consortium to Establish a Registry for Alzheimer's Disease, Korean version; CLU: Clusterin; CN: Cognitively normal; FDG: $\left[{ }^{18} \mathrm{~F}\right]$ fluoro-2-deoxyglucose; FH: Family history of Alzheimer's disease; GLM: General linear model; KBASE: Korean Brain Aging Study for the Early Diagnosis and Prediction of AD; MNI: Montreal Neurological Institute; MRI: Magnetic resonance imaging; PCC: Posterior cingulate cortex; PC-PRC: Posterior cingulate-precuneus; PET: Positron emission tomography; PiB: $\left[{ }^{11} \mathrm{C}\right]$ Pittsburg compound B; rCMglc: Regional cerebral glucose metabolism; ROI: Region of interest; SUVR: Standardized uptake value ratio
} 


\section{Acknowledgments}

We thank all study participants and their families for their contribution.

\section{Funding}

This study was supported by a grant from the Ministry of Science and ICT, Republic of Korea (grant no. NRF-2014M3C7A1046042). The funding source had no role in the study design, data collection, data analysis, data interpretation, writing of the manuscript, or decision to submit it for publication.

\section{Availability of data and materials}

The data generated and/or analyzed during the present study are available from the corresponding author on reasonable request.

\section{Authors' contributions}

DY was responsible for the acquisition, analysis, and interpretation of data, and drafting and critically revising the manuscript for intellectual content. $Y L$, $M S B, J H L$, and KK were responsible for the acquisition, analysis, and interpretation of data. BKS, YMC, HJC, HB, CHS, and YKK participated in analysis and interpretation of data. DYL was responsible for the study concept and design, acquisition of data, analysis, and interpretation of data, and drafting and critically revising the manuscript for intellectual content. All authors read and approved the final manuscript.

\section{Ethics approval and consent to participate}

This study was approved by Seoul National University Hospital's Institutional Review Board (IRB number 1401-027-547). All participants provided written informed consent to participate in this study after receiving a complete description of the study.

\section{Consent for publication}

Not applicable.

\section{Competing interests}

The authors declare that they have no competing interests.

\section{Publisher's Note}

Springer Nature remains neutral with regard to jurisdictional claims in published maps and institutional affiliations.

\section{Author details}

'Institute of Human Behavioral Medicine, Medical Research Center Seoul National University, Seoul, Republic of Korea. ${ }^{2}$ Department of Neuropsychiatry, Seoul National University Hospital, Seoul, Republic of Korea. ${ }^{3}$ Department of Psychiatry, Sanggye Paik Hospital, Inje University College of Medicine, Seoul, Republic of Korea. ${ }^{4}$ Department of Neuropsychiatry, University of Ulsan College of Medicine, Ulsan University Hospital, Ulsan, Republic of Korea. ${ }^{5}$ Department of Neuropsychiatry, SMG-SNU Boramae Medical Center, Seoul, Republic of Korea. ${ }^{6}$ Department of Neuropsychiatry, Kyunggi Provincial Hospital for the Elderly, Yongin, Republic of Korea. ${ }^{7}$ Department of Radiology, Seoul National University College of Medicine \& Seoul National University Hospital, Seoul, Republic of Korea. ${ }^{8}$ Department of Nuclear Medicine, SMG-SNU Boramae Medical Center, Seoul, Republic of Korea. ${ }^{9}$ Department of Psychiatry, Seoul National University College of Medicine, 101 Daehak-ro, Jongno-gu, Seoul 03080, Republic of Korea.

Received: 19 December 2017 Accepted: 23 July 2018

Published online: 23 August 2018

\section{References}

1. Chetelat G, La Joie R, Villain N, Perrotin A, de La Sayette V, Eustache F, Vandenberghe R. Amyloid imaging in cognitively normal individuals, at-risk populations and preclinical Alzheimer's disease. Neuroimage Clin. 2013;2: 356-65.

2. Corder EH, Saunders AM, Strittmatter WJ, Schmechel DE, Gaskell PC, Small $G W$, Roses AD, Haines JL, Pericak-Vance MA. Gene dose of apolipoprotein E type 4 allele and the risk of Alzheimer's disease in late onset families. Science. 1993;261(5123):921-3.

3. Jagust WJ, Landau SM, Alzheimer's Disease Neuroimaging Inititative. Apolipoprotein E, not fibrillar beta-amyloid, reduces cerebral glucose metabolism in normal aging. J Neurosci. 2012;32(50):18227-33.
4. Rowe CC, Ellis KA, Rimajova M, Bourgeat P, Pike KE, Jones G, Fripp J, Tochon-Danguy H, Morandeau L, O'Keefe G, et al. Amyloid imaging results from the Australian Imaging, Biomarkers and Lifestyle (AIBL) study of aging. Neurobiol Aging. 2010;31(8):1275-83.

5. Lowe VJ, Weigand SD, Senjem ML, Vemuri P, Jordan L, Kantarci K, Boeve B, Jack CR Jr, Knopman D, Petersen RC. Association of hypometabolism and amyloid levels in aging, normal subjects. Neurology. 2014;82(22):1959-67.

6. Didic M, Felician O, Gour N, Bernard R, Pecheux C, Mundler O, Ceccaldi M, Guedj E. Rhinal hypometabolism on FDG PET in healthy APO-E4 carriers: impact on memory function and metabolic networks. Eur J Nucl Med Mol Imaging. 2015;42(10):1512-21.

7. Knopman DS, Jack CR Jr, Wiste HJ, Lundt ES, Weigand SD, Vemuri P, Lowe VJ, Kantarci K, Gunter JL, Senjem ML, et al. 18F-fluorodeoxyglucose positron emission tomography, aging, and apolipoprotein E genotype in cognitively normal persons. Neurobiol Aging. 2014;35(9):2096-106.

8. Bozoki AC, Zdanukiewicz M, Zhu DC, Alzheimer's Disease Neuroimaging Initiative. The effect of beta-amyloid positivity on cerebral metabolism in cognitively normal seniors. Alzheimers Dement. 2016;12(12):1250-8.

9. Risacher SL, Kim S, Nho K, Foroud T, Shen L, Petersen RC, Jack CR Jr, Beckett LA, Aisen PS, Koeppe RA, et al. APOE effect on Alzheimer's disease biomarkers in older adults with significant memory concern. Alzheimers Dement. 2015;11(12):1417-29.

10. Reiman EM, Chen K, Alexander GE, Caselli RJ, Bandy D, Osborne D, Saunders AM, Hardy J. Functional brain abnormalities in young adults at genetic risk for late-onset Alzheimer's dementia. Proc Natl Acad Sci U S A. 2004;101(1):284-9.

11. Jansen WJ, Ossenkoppele R, Knol DL, Tijms BM, Scheltens P, Verhey FR, Visser PJ, Amyloid Biomarker Study Group, Aalten P, Aarsland D, et al. Prevalence of cerebral amyloid pathology in persons without dementia: a meta-analysis. JAMA. 2015;313(19):1924-38.

12. Gatz M, Reynolds CA, Fratiglioni L, Johansson B, Mortimer JA, Berg S, Fiske $A$, Pedersen NL. Role of genes and environments for explaining Alzheimer disease. Arch Gen Psychiatry. 2006;63(2):168-74.

13. Ganguli M, Kukull WA. Lost in translation: epidemiology, risk, and Alzheimer disease. Arch Neurol. 2010;67(1):107-11.

14. Migliore L, Coppede F. Genetics, environmental factors and the emerging role of epigenetics in neurodegenerative diseases. Mutat Res. 2009;667(1-2):82-97.

15. Qiu C, De Ronchi D, Fratiglioni L. The epidemiology of the dementias: an update. Curr Opin Psychiatry. 2007;20(4):380-5.

16. Mosconi L, Rinne JO, Tsui WH, Murray J, Li Y, Glodzik L, McHugh P, Williams S, Cummings M, Pirraglia E, et al. Amyloid and metabolic positron emission tomography imaging of cognitively normal adults with Alzheimer's parents. Neurobiol Aging. 2013;34(1):22-34.

17. Mosconi L, Murray J, Tsui WH, Li Y, Spector N, Goldowsky A, Williams S, Osorio R, McHugh P, Glodzik L, et al. Brain imaging of cognitively normal individuals with 2 parents affected by late-onset AD. Neurology. 2014;82(9): 752-60.

18. Murray J, Tsui WH, Li Y, McHugh P, Williams S, Cummings M, Pirraglia E, Solnes L, Osorio R, Glodzik L, et al. FDG and amyloid PET in cognitively normal individuals at risk for late-onset Alzheimer's disease. Adv J Mol Imaging. 2014;4(2):15-26.

19. Sager MA, Hermann B, La Rue A. Middle-aged children of persons with Alzheimer's disease: APOE genotypes and cognitive function in the Wisconsin registry for Alzheimer's prevention. J Geriatr Psychiatry Neurol. 2005;18(4):245-9.

20. Scarabino D, Gambina G, Broggio E, Pelliccia F, Corbo RM. Influence of family history of dementia in the development and progression of late-onset Alzheimer's disease. Am J Med Genet B Neuropsychiatr Genet. 2016;171B(2):250-6.

21. Byun MS, Yi D, Lee JH, Choe YM, Sohn BK, Lee JY, Choi HJ, Baek H, Kim YK, Lee YS, et al. Korean brain aging study for the early diagnosis and prediction of Alzheimer's disease: methodology and baseline sample characteristics. Psychiatry Investig. 2017;14(6):851-63.

22. Lee JH, Lee KU, Lee DY, Kim KW, Jhoo JH, Kim JH, Lee KH, Kim SY, Han SH, Woo Jl. Development of the Korean version of the consortium to establish a registry for Alzheimer's disease assessment packet (CERAD-K): clinical and neuropsychological assessment batteries. J Gerontol B Psychol Sci Soc Sci. 2002;57(1):47-53.

23. Morris JC. The clinical dementia rating (CDR): current version and scoring rules. Neurology. 1993;43(11):2412-4.

24. Lee DY, Lee KU, Lee JH, Kim KW, Jhoo JH, Kim SY, Yoon JC, Woo SI, Ha J, Woo Jl. A normative study of the CERAD neuropsychological assessment battery in the Korean elderly. J Int Neuropsychol Soc. 2004;10(1):72-81. 
25. Wenham PR, Price WH, Blandell G. Apolipoprotein E genotyping by onestage PCR. Lancet. 1991;337(8750):1158-9.

26. Tzourio-Mazoyer N, Landeau B, Papathanassiou D, Crivello F, Etard O, Delcroix N, Mazoyer B, Joliot M. Automated anatomical labeling of activations in SPM using a macroscopic anatomical parcellation of the MNI MRI single-subject brain. Neuroimage. 2002;15(1):273-89.

27. Reiman EM, Chen K, Liu X, Bandy D, Yu M, Lee W, Ayutyanont N, Keppler J, Reeder SA, Langbaum JB, et al. Fibrillar amyloid-beta burden in cognitively normal people at 3 levels of genetic risk for Alzheimer's disease. Proc Natl Acad Sci U S A. 2009:106(16):6820-5.

28. Villeneuve S, Rabinovici GD, Cohn-Sheehy Bl, Madison C, Ayakta N, Ghosh PM, La Joie R, Arthur-Bentil SK, Vogel JW, Marks SM, et al. Existing Pittsburgh compound-B positron emission tomography thresholds are too high: statistical and pathological evaluation. Brain. 2015;138(Pt 7):2020-33.

29. Forman SD, Cohen JD, Fitzgerald M, Eddy WF, Mintun MA, Noll DC Improved assessment of significant activation in functional magnetic resonance imaging (fMRI): use of a cluster-size threshold. Magn Reson Med. 1995;33(5):636-47.

30. Kim KW, Jhoo JH, Lee KU, Lee DY, Lee JH, Youn JY, Lee BJ, Han SH, Woo Jl. Association between apolipoprotein E polymorphism and Alzheimer's disease in Koreans. Neurosci Lett. 1999;277(3):145-8.

31. Turton JC, Bullock J, Medway C, Shi H, Brown K, Belbin O, Kalsheker N, Carrasquillo MM, Dickson DW, Graff-Radford NR, et al. Investigating statistical epistasis in complex disorders. J Alzheimers Dis. 2011;25(4):635-44.

32. Shao H, Burrage LC, Sinasac DS, Hill AE, Ernest SR, O'Brien W, Courtland HW, Jepsen KJ, Kirby A, Kulbokas EJ, et al. Genetic architecture of complex traits: large phenotypic effects and pervasive epistasis. Proc Natl Acad Sci U S A. 2008;105(50):19910-4.

33. Harold D, Abraham R, Hollingworth P, Sims R, Gerrish A, Hamshere ML, Pahwa JS, Moskvina V, Dowzell K, Williams A, et al. Genome-wide association study identifies variants at CLU and PICALM associated with Alzheimer's disease. Nat Genet. 2009:41(10):1088-93.

34. Lambert JC, Heath S, Even G, Campion D, Sleegers K, Hiltunen M, Combarros O, Zelenika D, Bullido MJ, Tavernier B, et al. Genome-wide association study identifies variants at CLU and CR1 associated with Alzheimer's disease. Nat Genet. 2009:41(10):1094-9.

35. DeMattos RB, Cirrito JR, Parsadanian M, May PC, O'Dell MA, Taylor JW, Harmony JA, Aronow BJ, Bales KR, Paul SM, et al. ApoE and clusterin cooperatively suppress Abeta levels and deposition: evidence that ApoE regulates extracellular Abeta metabolism in vivo. Neuron. 2004;41(2):193-202.

36. Holtzman DM. In vivo effects of ApoE and clusterin on amyloid-beta metabolism and neuropathology. J Mol Neurosci. 2004;23(3):247-54.

37. Tan MS, Yu JT, Tan L. Bridging integrator 1 (BIN1): form, function, and Alzheimer's disease. Trends Mol Med. 2013;19(10):594-603.

38. Zhou Y, Hayashi I, Wong J, Tugusheva K, Renger JJ, Zerbinatti C. Intracellular clusterin interacts with brain isoforms of the bridging integrator 1 and with the microtubule-associated protein Tau in Alzheimer's disease. PLoS One. 2014;9(7):e103187.

39. Van Cauwenberghe C, Van Broeckhoven C, Sleegers K. The genetic landscape of Alzheimer disease: clinical implications and perspectives. Genet Med. 2016:18(5):421-30.

40. Farrer LA, Cupples LA, Haines JL, Hyman B, Kukull WA, Mayeux R, Myers RH, Pericak-Vance MA, Risch N, van Duijn CM. Effects of age, sex, and ethnicity on the association between apolipoprotein E genotype and Alzheimer disease. A meta-analysis. APOE and Alzheimer disease Meta analysis consortium. JAMA. 1997;278(16):1349-56.

41. Ridge PG, Hoyt KB, Boehme K, Mukherjee S, Crane PK, Haines JL, Mayeux R, Farrer LA, Pericak-Vance MA, Schellenberg GD, et al. Assessment of the genetic variance of late-onset Alzheimer's disease. Neurobiol Aging. 2016;41: 200. e213-200 e220

42. Hendrie HC, Smith-Gamble V, Lane KA, Purnell C, Clark DO, Gao S. The association of early life factors and declining incidence rates of dementia in an elderly population of African Americans. J Gerontol B Psychol Sci Soc Sci. 2018;73(suppl_1):S82-9.

43. Moceri VM, Kukull WA, Emanuel I, van Belle G, Larson EB. Early-life risk factors and the development of Alzheimer's disease. Neurology. 2000;54(2):415-20

44. Calderon-Garciduenas L, Gonzalez-Maciel A, Reynoso-Robles R, DelgadoChavez R, Mukherjee PS, Kulesza RJ, Torres-Jardon R, Avila-Ramirez J, Villarreal-Rios R. Hallmarks of Alzheimer disease are evolving relentlessly in metropolitan Mexico City infants, children and young adults. APOE4 carriers have higher suicide risk and higher odds of reaching NFT stage $V$ at $</=40$ years of age. Environ Res. 2018;164:475-87.

45. Borenstein AR, Copenhaver Cl, Mortimer JA. Early-life risk factors for Alzheimer disease. Alzheimer Dis Assoc Disord. 2006:20(1):63-72.

46. Cohen S, Janicki-Deverts D, Chen E, Matthews KA. Childhood socioeconomic status and adult health. Ann N Y Acad Sci. 2010;1186:37-55.

47. Ko K, Byun MS, Yi D, Lee JH, Kim CH, Lee DY. Early-life cognitive activity is related to reduced neurodegeneration in Alzheimer signature regions in late life. Front Aging Neurosci. 2018;10:70.

48. Jack CR Jr, Knopman DS, Jagust WJ, Shaw LM, Aisen PS, Weiner MW, Petersen RC, Trojanowski JQ. Hypothetical model of dynamic biomarkers of the Alzheimer's pathological cascade. Lancet Neurol. 2010;9(1):119-28.

49. Jagust WJ, Bandy D, Chen K, Foster NL, Landau SM, Mathis CA, Price JC, Reiman EM, Skovronsky D, Koeppe RA, et al. The Alzheimer's disease neuroimaging initiative positron emission tomography core. Alzheimers Dement. 2010;6(3):221-9.

\section{Ready to submit your research? Choose BMC and benefit from:}

- fast, convenient online submission

- thorough peer review by experienced researchers in your field

- rapid publication on acceptance

- support for research data, including large and complex data types

- gold Open Access which fosters wider collaboration and increased citations

- maximum visibility for your research: over $100 \mathrm{M}$ website views per year

At BMC, research is always in progress.

Learn more biomedcentral.com/submissions 